Published by Al-Nahrain College of Medicine P-ISSN 1681-6579

E-ISSN 2224-4719

Email: iraqijms@colmed-alnahrain.edu.iq

http://www.colmed-alnahrain.edu.iq

http://www.iraqijms.net

Iraqi JMS 2018; Vol. 16(1)

\title{
Evaluation of the Anti-Inflammatory Effect of Telmisartan As an Adjuvant Therapy to NSAID in The Management of Knee Osteoarthritis; A Clinical Prospective Study
}

\author{
Sarah A. Hmood ${ }^{1}$ MSc, Mohammed M. Mohammed ${ }^{1}$ PhD, Yassir M. Kamal ${ }^{2}$ PhD, Nizar A. Jasim ${ }^{3}$ \\ PhD
}

${ }^{1}$ Dept. of Clinical Pharmacy, ${ }^{2}$ Dept. of Pharmacology and Toxicology, College of Pharmacy, Al-Mustansiriyah University, ${ }^{3}$ Dept. of Rheumatology, College of Medicine, University of Baghdad, Baghdad, Iraq

\begin{abstract}
Background Osteoarthritis $(\mathrm{OA})$ is a degenerative joint disease caused by gradual loss of cartilage. Telmisartan is an angiotensin II receptor antagonist, and act as a partial agonist on the nuclear peroxisome proliferatoractivated receptor-gamma (PPAR- $\gamma$ ), that has been reported to exert anti-inflammatory effects.

Objective To evaluate the potential anti-inflammatory effect of telmisartan in patients with knee OA.

Methods $\quad$ Forty-two patients with painful knee OA were allocated into 2 groups, group (1): patients treated with naproxen tablets $(500 \mathrm{mg} / 12 \mathrm{hr}$ ), telmisartan tablets $(40 \mathrm{mg} /$ day) and omeprazole $(20 \mathrm{mg} /$ day) for 3 months, while group (2): patients treated with naproxen tablets $(500 \mathrm{mg} / 12 \mathrm{hr}$ ) and omeprazole $(20 \mathrm{mg} /$ day $)$ for 3 months. The serum levels of IL-1 $\beta$, high-sensitivity C-reactive protein (hs-CRP), TNF- $\alpha$ and erythrocyte sedimentation rate (ESR) were measured before and after 3 months of treatment.

Results Telmisartan when used in combination with naproxen resulted in significant decrease in serum levels of IL-1 $\beta$ and hs-CRP, higher than that produced by naproxen when used alone. The mean TNF- $\alpha$ level and ESR was decreased non-significantly in both study groups.

Conclusion Administration of telmisartan as an adjuvant therapy to naproxen in knee OA patients produced a significant decrease in the serum levels of IL-1 $\beta$ and hs-CRP, though no clear effect on TNF- $\alpha$ and ESR was noticed after 3 months treatment. Accordingly, many promising preventive strategies emerged from the available results since telmisartan relatively reduce the inflammatory burden in OA patients. The dose and duration of telmisartan treatment in this study did not indicate a risk of hypotension.

Keywords Telmisartan, naproxen, osteoarthritis, cytokines

Citation

Hmood SA, Mohammed MM, Kamal YM, Jasim NA. Evaluation of the anti-inflammatory effect of telmisartan as an adjuvant therapy to NSAID in the management of knee osteoarthritis; a clinical prospective study. Iraqi JMS. 2018; Vol. 16(1): 100-110. doi: 10.22578/IJMS.16.1.14
\end{abstract}

List of abbreviations: $\mathrm{CK}=$ Creatine kinase, $\mathrm{COX}-2=$ Cyclooxygenase 2, DMOADs = Disease-modifying osteoarthritis drugs, ELISA = Enzyme-linked immunosorbent assay, ESR = Erythrocyte sedimentation rate, hs-CRP = Highsensitivity C-reactive protein, IL-17 = Interleukin- $17, \mathrm{KL}=$ Kellgren-Lawrence, IL$1 \beta=$ Interleukin- 1 beta, IL- $6=$ Interleukin- 6, iNOS = Inducible nitric oxide synthase, MMP-1 = Matrix metaloproteinase-1, MMPs = Matrix metalloproteinases, mPGES-1 $=$ Microsomal prostaglandin E synthase-1, NSAIDs $=$ Non-steroidal antiinflammatory drugs, $\mathrm{OA}=$ Osteoarthritis, $\mathrm{PGE2}=$ Prostaglandin E2, PPAR $-\gamma=$ Peroxisome proliferator-activated receptor-gamma, TENS $=$ Transcutaneous electrical nerve stimulation, TNF- $\alpha=$ Tumor necrosis factor-alpha

\section{Introduction}

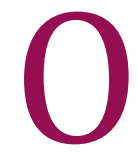
steoarthritis (OA) is a degradative joint disease occurs due to gradual loss of cartilage and resulting in bony spurs and cysts formation at joint edges (1). It is a pathological result of several disorders, which cause functional impairment of synovial joints (2). Primary $O A$ is related to aging, while secondary OA tends to show up earlier in life, often due to a specific cause such as an injury, diabetes, or obesity ${ }^{(3)}$. The major risk factor for $\mathrm{OA}$ are family history ${ }^{(4)}$, obesity, older age, female gender, previous knee injury and the presence of hand OA/Heberden's nodes (5). Clinical features of OA include pain, stiffness ${ }^{(6)}$, 
crepitus, restricted joint motion, joint deformity, joint tenderness, effusion and muscle atrophy (7). The diagnosis of $O A$ is usually based on clinical and radiological features ${ }^{(8)}$. A typical plain X-ray of OA may elucidate one or more of the following features; (1) Joint space narrowing, (2) Subchondral sclerosis, (3) Peripheral osteophytes, (4) Subchondral cysts ${ }^{(9)}$. Normal adult articular cartilage is made up of extracellular matrix (water, collagen, proteoglycans and calcium salt) and chondrocytes ${ }^{(10)}$. Inability of chondrocytes to provide homeostasis between degradation of extracellular matrix ingredients and synthesis lead to $O A{ }^{(11)}$. A severe subchondral bone modifying lead to sclerosis of the tissue noticeable radiographically. These changes are often coexisted with subchondral cysts formation due to resorption (12). Synovitis is believed to be induced at first by the cartilage matrix proteolytic degradation products (13). Synoviocytes can produce inflammatory cytokines; proinflammatory cytokines such as interleukin-1 beta (IL-1 $\beta$ ) and tumor necrosis factor-alpha (TNF- $\alpha$ ), these cytokines are considered to interpose the degeneration related to OA (14). Non-pharmacological management of OA includes exercise (15), weight reduction (16), balneotherapy ${ }^{(17)}$, knee braces (18), self-management (19), transcutaneous electrical nerve stimulation (TENS) ${ }^{(20)}$, acupuncture (21) and nutraceuticals (22). Pharmacological treatment of OA includes acetaminophen (23), oral non-steroidal antiinflammatory drugs (NSAIDs) (24), topical NSAIDs (23), intraarticular (IA) injections of corticosteroids (25), IA injection of hyaluronic acid (23), opioid analgesics (26), and diseasemodifying osteoarthritis drugs (DMOADs) (27). Surgical procedures are generally accepted in patients who are not obtaining adequate pain relief with a combination of pharmacological and non-pharmacological treatments (28). The discovery that several factors such as cytokines or prostaglandins can raise the levels of matrix metalloproteinases (MMPs) by chondrocytes led to an inflammatory concept. $O A$ is a complicated disease with inflammatory mediators liberated by the cartilage, bone and synovium ${ }^{(29,30)}$. These inflammatory mediators represent potential targets for therapeutic interventions designed to reduce both symptoms and structural joint damage in $\mathrm{OA}$ (31). Cyclooxygenase-2 (COX-2) is a major Prostaglandin E2 (PGE2) synthetic enzyme and implicated in the pathogenesis of inflammation and pain in OA (32). Cyclooxygenase-2 is upregulated in inflamed joint, its accountable for increased level of PGE2 in OA joint. PGE2 is implicated in inflammation, apoptosis, angiogenesis, and potentially morphological alteration in arthritis ${ }^{(33)}$. Over expression of COX-2 is mostly stimulated by proinflammatory mediators such as IL- $1 \beta$, TNF- $\alpha$, and IL-6 (interleukin-6) stimulation (34). Proinflammatory cytokines are thought to have an essential role in OA pathophysiology, in particular IL-1 $\beta$ and TNF- $\alpha{ }^{(35)}$. TNF- $\alpha$ operate the inflammatory cascade, while $\mathrm{IL}-1 \beta$ is significant for cartilage destruction (36).

Telmisartan a highly selective AT1 receptor (Angiotensin II receptor, type 1) antagonist, it is a partial agonist on peroxisome proliferatoractivated receptor-gamma (PPAR- $\psi$ ), which improved to have anti-oxidative and antiinflammatory actions. PPAR- $\gamma$ partial agonist activity improves metabolic and inflammatory cascade ${ }^{(37)}$. Peroxisome proliferator-activated receptors (PPARs) are present in three types: PPAR- $\alpha$, PPAR- $\beta / \delta$, and PPAR- $\gamma$ (38), they produce anti-inflammatory actions by preventing pro-inflammatory cytokines induction, adhesion molecules and extracellular matrix proteins production, or by enhancing the induction of anti-inflammatory particles. In addition, PPARs control the proliferation, differentiation and survival of immune cells as macrophages, B cells and T cells ${ }^{(39)}$. Several lines proposed that the PPARY activation in $O A$ may be therapeutically interested, PPARY is functionally active in chondrocytes, and its activation modify the expression of several genes demonstrated to 
be important in OA pathogenesis. PPARY activation inhibits production of nitric oxide synthase, matrix metaloproteinase-13 (MMP13), COX-2, and microsomal prostaglandin $E$ synthase-1 (mPGES-1) in chondrocytes by inhibiting IL-1 induction (40,41). In addition, activation of PPARY inhibits proteoglycan degeneration which caused by IL-1 induction (42). PPARy activation in synovial fibroblasts inhibits IL-1, TNF- $\alpha$ and matrix metaloproteinase-1 (MMP-1) expression (43). The effect of PPARy activators has been demonstrated in many animal models of $O A$ as guinea-pig (44). Treatment of human OA chondrocytes with PPARY agonist decreased nitric oxide, PGE2, inducible nitric oxide synthase (iNOS) and COX-2 expression (45). The induction of NO production by interleukin-17 (IL-17) and TNF- $\alpha$ was also inhibited upon PPARY activation (45). Decreased expression of PPARY in OA cartilage may resulted in increased production of inflammatory and catabolic genes, enhancing cartilage degradation. Diminished PPARY expression in OA cartilage supporting PPARy role in OA, and increase the possibility that upregulation of PPARY may be beneficial in OA treatment (46). Clockaerts et al concluded that PPAR- $\alpha$ activation results in anti-inflammatory effects in human OA cartilage (47). Telmisartan decreased formaldehyde-induced chronic inflammation in rats in a dose-dependent pattern (48). This study was designed to evaluate the potential anti-inflammatory effect of telmisartan in patients with knee OA.

\section{Methods}

This is a prospective randomized controlled open-label interventional study to evaluate the anti-inflammatory effect of telmisartan in the treatment of patients with painful knee OA. The study was conducted during the period from September 2015 to May 2016 and carried out on 42 randomly selected Iraqi patients newly diagnosed with knee $\mathrm{OA}$; at the outpatient clinic at Baghdad Teaching Hospital. All patients have symptomatic and radiologic evidence of $\mathrm{OA}$ in one or both knee joints.
Ethical approval was obtained from Ethics Committee by Pharmacy College/ University of AL-Mustansyriah, and Baghdad Teaching Hospital. All subjects gave written informed consent to participate in the study. Patients were diagnosed based on clinical and radiological features depending on KellgrenLawrence (KL) classification system ${ }^{(49)}$. Certain exclusion criteria were followed to avoid interference with the study design, include: patients with hypertension, ischemic heart diseases, asthma or diabetes mellitus; patients who are on treatment with drugs, which interfere with the tested drugs, patients with peptic ulcer, patients with end-stage radiological events of joint destruction, patients with positive history of allergic reactions to any one of the known tested drugs, and pregnant or lactating patients. The selected patients were allocated into two main groups as following: group (1): includes 22 patients with knee OA treated with naproxen tablets $\left(500 \mathrm{mg} / 12 \mathrm{hr}\right.$ ), telmisartan (Micardis ${ }^{\circledR}$ tablets $40 \mathrm{mg} /$ day) and omeprazole (20 $\mathrm{mg} /$ day) for three months, while group (2): includes 20 patients with knee OA treated with naproxen tablets $(500 \mathrm{mg} / 12 \mathrm{hr})$ and omeprazole $(20 \mathrm{mg} /$ day $)$ for three months. Omeprazole $20 \mathrm{mg}$ used in this study as a primary prophylaxis against NSAID-associated ulcer disease or dyspeptic symptoms.

Ten milliliters of venous blood were drawn from fasting patients, at baseline and after three months of treatment to follow up the changes in IL-1 $\beta$, high-sensitivity C-reactive protein (hs-CRP), TNF- $\alpha$ and erythrocyte sedimentation rate (ESR). Blood samples were allowed to clot, then separated by centrifuge at speed of $3000 \mathrm{rpm}$ for 10 minutes and stored at $\left(-40^{\circ} \mathrm{C}\right)$ until the time of examination for IL$1 \beta$, TNF- $\alpha$ and hs-CRP, unless worked immediately for the evaluation of ESR. Serum level of IL-1 $\beta$, TNF- $\alpha$ and hs-CRP were determined using commercial enzyme-linked immunosorbent assay (ELISA) kit (Elabscience Biotechnology, China), while ESR was measured using Westergren method (50). 


\section{Statistical analysis}

The statistical analysis system- Minitab 16.1 (2010) was used. Data were expressed as (mean \pm standard error "SE"). Chi-square test was utilized to detect significant differences among demographic variables, while paired ttest was used to compare between pre- and post-treatment results in same group, independent $\mathrm{t}$ - test used to compare pre- or post- treatment between group 1 and group 2 . $P$ value $(<0.05)$ considered significant difference, $P$ value $(<0.01)$ considered highly significant difference.

\section{Results}

The demographic and baseline disease characteristics were evenly distributed for both groups as summarized in table 1.

After adjustment of baseline mean of patients' demographic and disease characteristics. There was no significant statistical difference $(P>0.05)$ between both groups in respect to age, gender, $\mathrm{X}$-ray finding, BMI, waist circumference and joint deformity finding (table 1 ).

Table 1. Patients demographics and disease characteristics

\begin{tabular}{|c|c|c|c|c|}
\hline \multirow{2}{*}{\multicolumn{2}{|c|}{ Variable }} & \multicolumn{2}{|c|}{ Study Groups } & \multirow{2}{*}{$P$-value } \\
\hline & & Group 1 & Group 2 & \\
\hline \multicolumn{2}{|l|}{$\begin{array}{l}\text { Age ( years) } \\
\text { mean } \pm S E\end{array}$} & $51.91 \pm 1.9$ & $47.65 \pm 1.4$ & $0.084^{\mathrm{NS}}$ \\
\hline \multicolumn{2}{|l|}{$\begin{array}{c}\mathrm{BMI}\left(\mathrm{kg} / \mathrm{m}^{2}\right) \\
\text { mean } \pm \mathrm{SE}\end{array}$} & $35.62 \pm 1.2$ & $33.74 \pm 1.5$ & $0.340^{\mathrm{NS}}$ \\
\hline \multicolumn{2}{|c|}{$\begin{array}{l}\text { Waist circumference }(\mathrm{cm}) \\
\text { mean } \pm S E\end{array}$} & $113.95 \pm 1.9$ & $109.30 \pm 3.0$ & 0.196 NS \\
\hline Gender (n (\%)) & $\begin{array}{l}\text { Female } \\
\text { Male }\end{array}$ & $\begin{array}{l}16(72.72) \\
6(27.27)\end{array}$ & $\begin{array}{l}17(85.0) \\
3(15.0)\end{array}$ & $0.333^{N S}$ \\
\hline $\begin{array}{l}\text { X-ray finding } \\
\text { (n (\%)) }\end{array}$ & $\begin{array}{l}\text { Grade I } \\
\text { Grade II } \\
\text { Grade III }\end{array}$ & $\begin{array}{c}5(22.7) \\
6(27.3) \\
11(50.0)\end{array}$ & $\begin{array}{l}6(30.0) \\
7(35.0) \\
7(35.0)\end{array}$ & $0.618^{N S}$ \\
\hline $\begin{array}{l}\text { Joint deformity finding } \\
\text { (n (\%)) }\end{array}$ & $\begin{array}{l}\text { Negative } \\
\text { Positive }\end{array}$ & $\begin{array}{l}15(68.0) \\
7(32.0)\end{array}$ & $\begin{array}{l}14(70.0) \\
6(30.0)\end{array}$ & $0.899^{N S}$ \\
\hline
\end{tabular}

Data presented as mean \pm standard error (SE), number of patients $(n)$ and percentage (\%). NS: No significant differences $(P>0.05),(*)$ significant differences $(P<0.05),\left({ }^{* *}\right)$ highly significant differences $(P<0.01)$. BMI: body mass index

The results showed that telmisartan, when used in combination with a non-steroidal antiinflammatory drug (naproxen) resulted in significant decrease $(P<0.05)$ in the serum levels of IL-1 $\beta$ (table 2 , figure 1 ), and a highly significant decrease $(P<0.01)$ in the serum levels of hs-CRP (table 3, figure 2), higher than that produced by naproxen when used alone. While the serum levels of TNF- $\alpha$ level and ESR was decreased non-significantly $(P>0.05)$ in both study groups, as shown in (table 4 , figure 3 ), and (table 5, figure 4) respectively. 
Table 2. Effects of treatment with naproxen alone, and combination of naproxen+ telmisartan on serum level of interleukin-1 beta (IL-1ß) in osteoarthritic patients

\begin{tabular}{cccc}
\hline \multirow{2}{*}{ IL-1 $\boldsymbol{\beta}(\mathrm{pg} / \mathrm{ml})$} & \multicolumn{2}{c}{ Study Groups } & \multirow{2}{*}{-value } \\
& Group 1 & Group 2 & \\
\hline Pre-treatment & $68.2 \pm 12.1$ & $135.4 \pm 37.9$ & $0.105^{\mathrm{NS}}$ \\
Post-treatment & $37.3 \pm 4.5$ & $84.4 \pm 16.0$ & $0.011^{*}$ \\
\hline $\boldsymbol{P}$-value & $0.016^{*}$ & $0.174^{\mathrm{NS}}$ & ---------- \\
\hline
\end{tabular}

Data presented as mean \pm standard error $(\mathrm{SE})$, NS: No significant differences $(P>0.05),\left({ }^{*}\right)$ significant differences $(P<0.05),\left(^{* *}\right)$ highly significant differences $(P<0.01)$

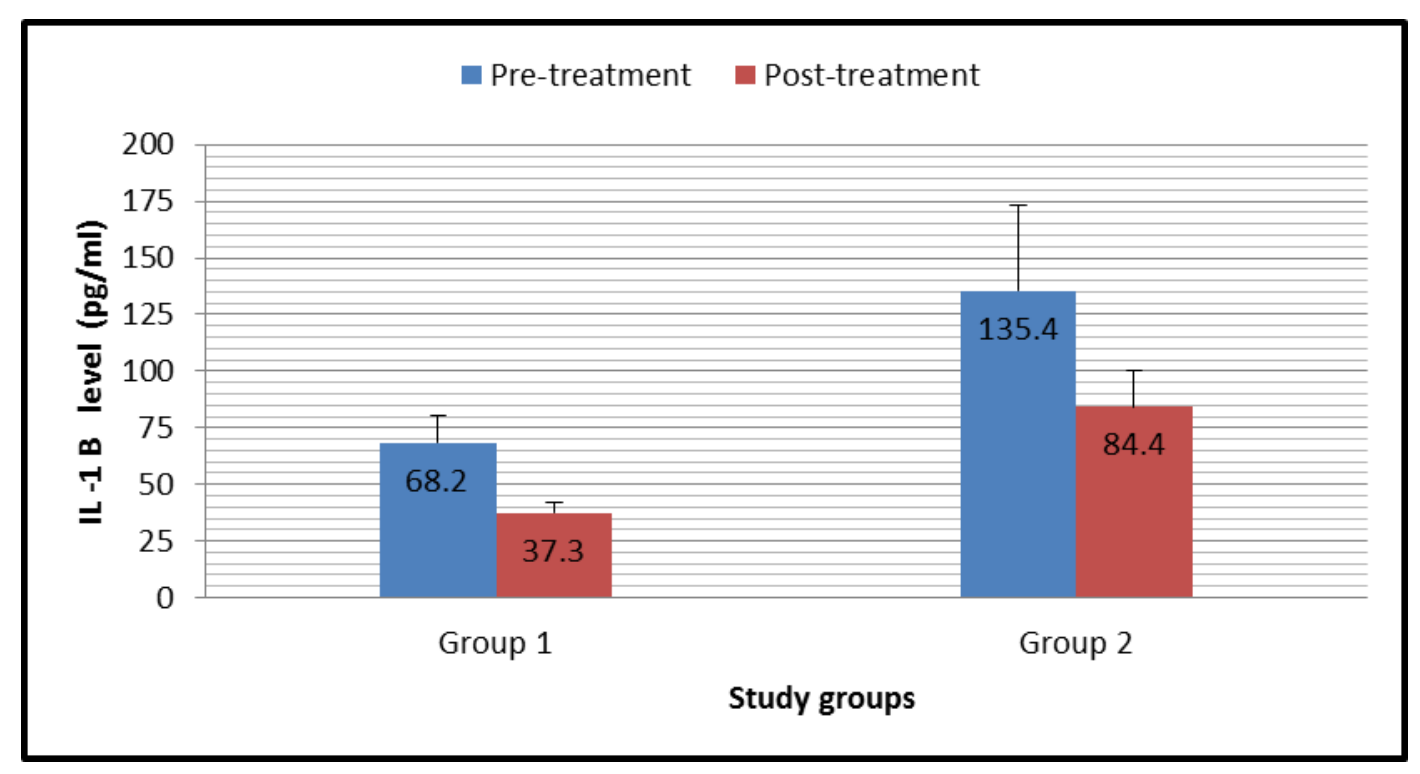

Figure 1. Effects of treatment with naproxen alone, and combination of naproxen+ telmisartan on serum level of interleukin-1 beta (IL-1ß) in osteoarthritic patients

Table 3. Effects of treatment with naproxen alone, and combination of naproxen+ telmisartan on serum level of high sensitivity c-reactive protein (hs-CRP) in osteoarthritic patients

\begin{tabular}{cccc}
\hline \multirow{2}{*}{ hs-CRP $(\mathrm{mg} / \mathrm{l})$} & \multicolumn{2}{c}{ Study Groups } & \multirow{2}{*}{-value } \\
& Group 1 & Group 2 & \\
\hline Pre-treatment & $8.74 \pm 1.2$ & $7.91 \pm 0.9$ & $0.589^{\mathrm{NS}}$ \\
Post-treatment & $6.12 \pm 0.8$ & $6.24 \pm 0.8$ & $0.916^{\mathrm{NS}}$ \\
\hline $\boldsymbol{P}$ - value & $0.009^{* *}$ & $0.012^{*}$ & --------- \\
\hline
\end{tabular}

Data presented as mean \pm standard error (SE), NS: No significant differences $(P>0.05),\left({ }^{*}\right)$ significant differences $(P<0.05),\left({ }^{* *}\right)$ highly significant differences $(P<0.01)$ 


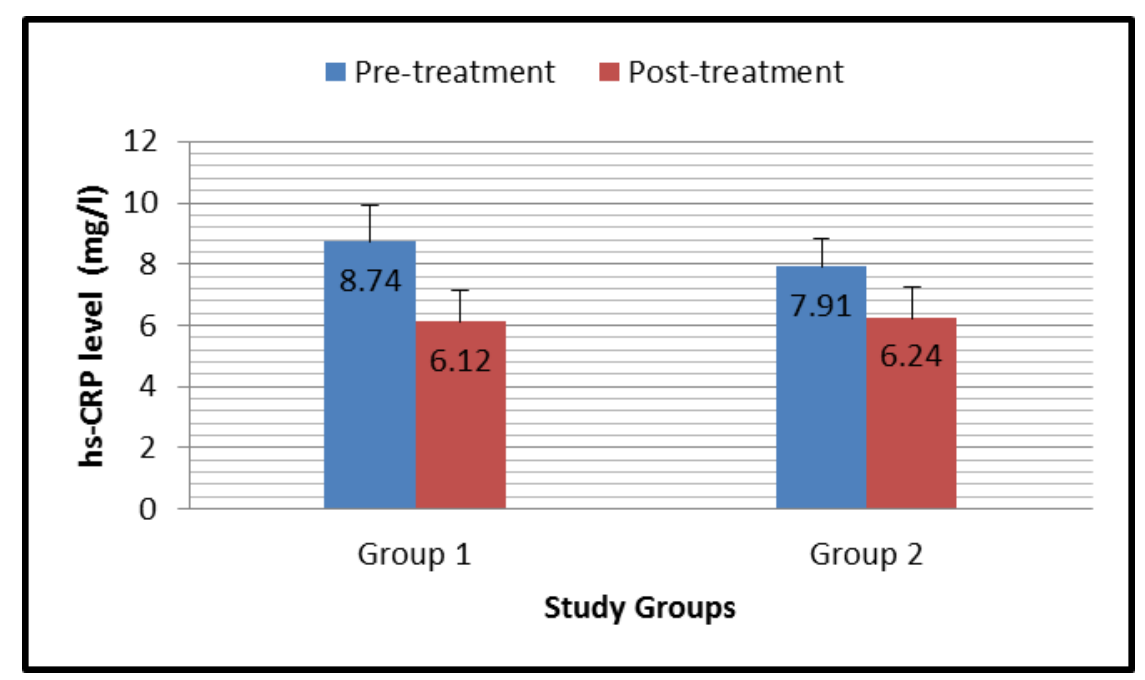

Figure 2. Effects of treatment with naproxen alone, and combination of naproxen+ telmisartan on serum level of high sensitivity c-reactive protein (hs-CRP) in osteoarthritic patients

Table 4. Effects of treatment with naproxen alone, and combination of naproxen+ telmisartan on serum level of tumor necrosis factor-alpha (TNF- $\alpha$ ) in osteoarthritic patients

\begin{tabular}{cccc}
\hline \multirow{2}{*}{ TNF- $\alpha(\mathrm{pg} / \mathrm{ml})$} & \multicolumn{2}{c}{ Study Groups } & \multirow{2}{*}{-value } \\
& Group 1 & Group 2 & \\
\hline Pre-treatment & $43.0 \pm 11.4$ & $46.81 \pm 9.1$ & $0.793^{\mathrm{NS}}$ \\
Post-treatment & $38.3 \pm 10.0$ & $37.9 \pm 11.0$ & $0.975^{\mathrm{NS}}$ \\
\hline $\boldsymbol{P}$-value & $0.520^{\mathrm{NS}}$ & $0.400^{\mathrm{NS}}$ & ---------- \\
\hline
\end{tabular}

Data presented as mean \pm standard error (SE), NS: No significant differences $(P>0.05),\left({ }^{*}\right)$ significant differences $(P<0.05),(* *)$ highly significant differences $(P<0.01)$

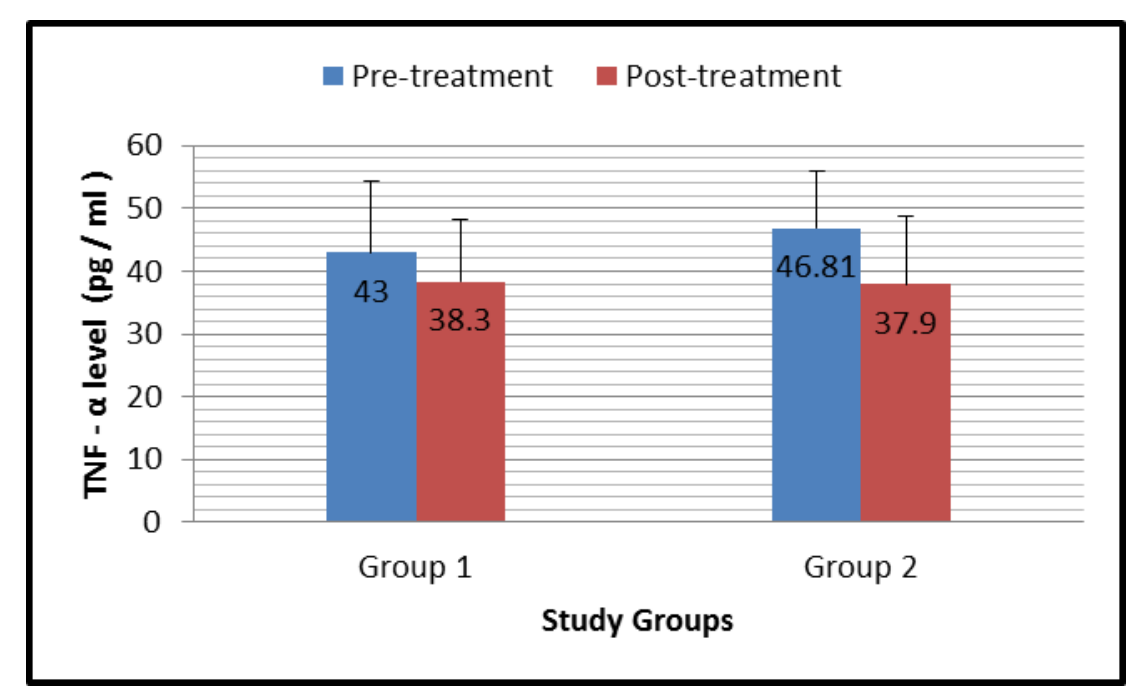

Figure 3: Effects of treatment with naproxen alone, and combination of naproxen+ telmisartan on serum level of tumor necrosis factor-alpha (TNF- $\alpha$ ) in osteoarthritic patients 
Table 5. Effects of treatment with naproxen alone, and combination of naproxen+ telmisartan on erythrocyte sedimentation rate (ESR) in osteoarthritic patients

\begin{tabular}{cccc}
\hline \multirow{2}{*}{ ESR (mm/hr) } & \multicolumn{2}{c}{ Study Groups } & \multirow{2}{*}{ P-value } \\
& Group 1 & Group 2 & \\
\hline Pre-treatment & $30.27 \pm 6.6$ & $17.55 \pm 2.1$ & 0.079 NS \\
Post-treatment & $19.1 \pm 3.0$ & $14.95 \pm 1.6$ & $0.230^{\mathrm{NS}}$ \\
\hline $\boldsymbol{P}$ - value & $0.105^{\mathrm{NS}}$ & $0.072^{\mathrm{NS}}$ & ---------- \\
\hline
\end{tabular}

Data presented as mean \pm standard error $(S E)$, NS: No significant differences $\left.(P>0.05),{ }^{*}\right)$ significant differences $(P<0.05),\left({ }^{* *}\right)$ highly significant differences $(P<0.01)$

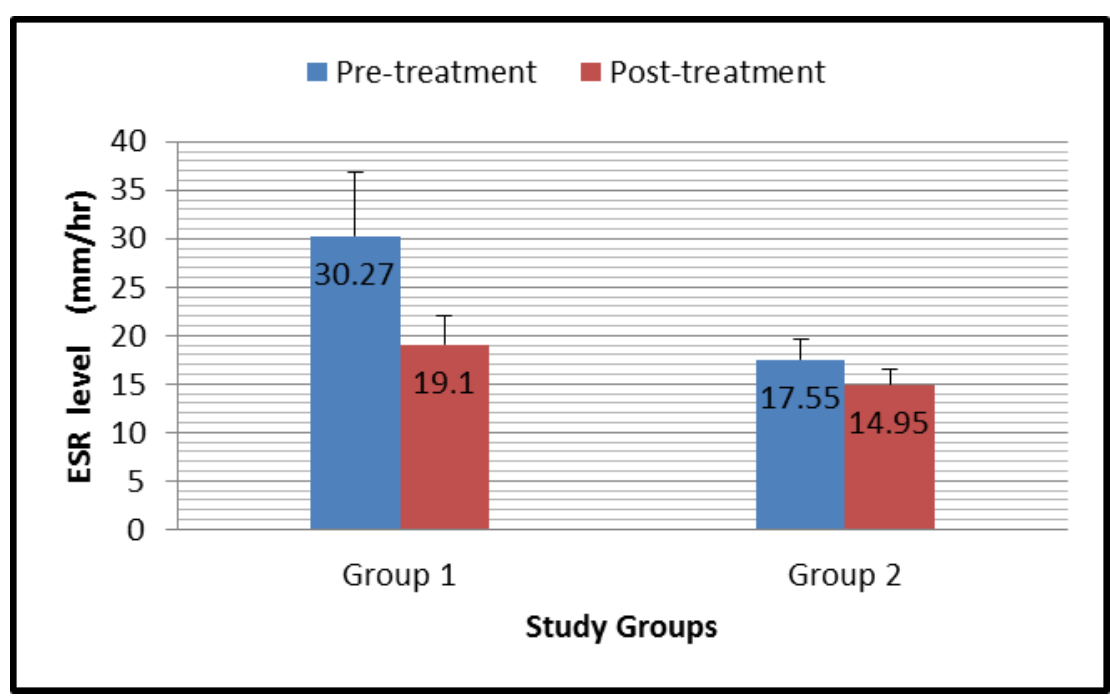

Figure 4: Effects of treatment with naproxen alone, and combination of naproxen+ telmisartan on erythrocyte sedimentation rate (ESR) in osteoarthritic patients

\section{Discussion}

Osteoarthritis is the leading cause of inability worldwide (51). Although telmisartan was developed to treat hypertension by blocking angiotensin II (type 1) receptor, the finding that telmisartan can activate PPARY has prospectively remarkable therapeutic modulations for treatment of other clinical diseases that might be responsive to PPARY activators ${ }^{(52)}$.

The ability of telmisartan to reduce the intensity of pain and inflammation that contributed to the pathophysiology of arthritis, with no serious adverse effects, has been reported in some animal model studies ${ }^{(53)}$. This may be considered a new therapeutic approach added to the current NSAIDs treatment for inflammation patients with knee
OA. Up to the best knowledge, there is no clinical study reported for Iraqi population to explore the role of telmisartan in OA. Thus, the present study was undertaken to clinically evaluate whether or not telmisartan can reduce the intensity of inflammation in knee OA patients.

As mentioned earlier, the pro-inflammatory cytokines TNF- $\alpha$ and IL-1 $\beta$, are among the critical mediators modulated in the pathophysiology of OA. These mediators regulate articular cartilage matrix degeneration, which makes them as major targets for treatment strategies. Although animal studies provide support for this approach, just a few studies have sought the effects of inhibiting these cytokines in OA (29). 
In the present study, significant decrease of mean IL-1 $\beta$ level in group 1 patients was found after three months, meanwhile group 2 showed no significant decrease of this antiinflammatory cytokine, which can be explained by the potential role of telmisartan in reduce concentrations of the pro-inflammatory cytokine IL-1 $\beta$ in group 1 , with the fact that naproxen therapy failed to control IL-1 $\beta$ level in group 2. Animal study on rats with periodontitis showed that telmisartan reduces the inflammatory response. Treatment with telmisartan reduced levels of IL-1 $\beta$, COX-2, MMP-2, MMP-9 and TNF- $\alpha{ }^{(54)}$. Animal study on brains of neonatal Wistar rats was aimed to illustrate the role of angiotensin system in the modulation of glial functions and Alzheimer's disease pathology. Telmisartan highly reduced the production of TNF- $\alpha$ and IL1- $\beta$ (by approximately $50 \%$ and $30 \%$, respectively) which already induced by lipopolysaccharide (LPS) ${ }^{(55)}$.

Animal study on ulcerative colitis in rats tested the anti-inflammatory effect of telmisartan. Telmisartan at $5 \mathrm{mg} / \mathrm{kg}$ exerts beneficial effects, these effects may be due to accelerated termination of acute inflammatory phase, due to decreasing TNF- $\alpha$ level (56). As mentioned previously, telmisartan decreased formaldehyde-induced chronic inflammation in rats in a dose-dependent pattern ${ }^{(48)}$. The doseresponse relationship of the anti-inflammatory activity of telmisartan was found to be relatively linear within the dose ranges utilized in the study, with best linearity between 0.6 and $3 \mathrm{mg} / \mathrm{kg}{ }^{(48)}$. The present study found that TNF- $\alpha$ decreased in both study groups ( 1 and 2 ) after three months treatment, but not significant. Higher doses might be required to explore the effect clearly. Recent study search for the effect of telmisartan on the proinflammatory mediators secreted from adipocytes. Telmisartan was dissolved in a vehicle, the study showed that higher dose of telmisartan $(1 \mu \mathrm{g} / \mathrm{ml})$ on adipocytes culture decreased the levels of TNF- $\alpha$, while lower dose of telmisartan $(0.1 \mu \mathrm{g} / \mathrm{ml})$ had nonsignificant effects on TNF- $\alpha$ levels (57).

Regarding hs-CRP in the present study, group 1 show a higher significant decrease in mean results of serum level of hs-CRP than group 2, suggesting the potential role of telmisartan. A study on Wistar rats was performed to research the effect of spironolactone, telmisartan, and their combination on isoproterenol-induced cardiac hypertrophy. The study concludes that chronic treatment with spironolactone, telmisartan, and their combination result in a significant decrease in the elevated levels of creatine kinase (CK) and CRP (58). A recent study aimed to investigate the effects of telmisartan on inflammation and fibrosis after myocardial infarction in rats, the study showed that levels of CRP, TNF $\alpha$, IL- 6 and IL-1 $\beta$ were decreased markedly in telmisartan group ${ }^{(59)}$.

The present study found that ESR decreased in both study groups ( 1 and 2 ) after three months treatment, but not significant. Longer duration of treatment and/or higher doses might be required to explore the effect clearly. Another study was aimed to estimate the potential effects of telmisartan in hypertensive HIVpositive patients with microalbuminuria. Males receiving stable combined antiretroviral therapy and $80 \mathrm{mg} /$ day telmisartan for 6 months. A significant decrease in ESR, which may be correlated to the protective effect of telmisartan ${ }^{(60)}$.

The present study has few limitations including small sample size with different disease severity, which required to verify the findings, short duration of patient follow up, as longer period may be required to explore a good result.

The current study concluded that: (1) Telmisartan when co-administered with naproxen, produced significant reduction in serum levels of IL-1 $\beta$, highly significant reduction in serum levels of hs-CRP, compared to that of using naproxen alone. (2) Telmisartan when co-administered with naproxen produced non-significant reduction in TNF- $\alpha$ and ESR levels. The present study have few limitation including small sample size with disease severity of different stages, which required to verify the findings, short duration of patient follow up. In addition, inattention blood pressure measurement to explore the hypotensive effect of telmisartan in 
normotensive patients. In the current study, many promising preventive strategies emerged from the available results since telmisartan relatively reduce the inflammatory burden in OA patients, suggesting that telmisartan plays effective role to be a good candidate as an adjuvant therapy. Further investigations for all drugs in angiotensin receptor blocker group for their pleiotropic effect must be undertaken so that new indications of these drugs can come to light.

\section{Acknowledgments}

The authors would like to thank AlMustansiriyah University (www.uomustansiriyah.edu.iq) and Baghdad Teaching Hospital, Iraq for their help in providing the practical platform of this study.

\section{Authors Contribution:}

Dr. Hmood and Dr. Mohammed and collected the data and analyzed it; Dr. Kamal arranged it and supervised the study; and Dr. Jasim interpreted and arranged drafting of this paper.

\section{Conflict of interest}

There is no conflict of interest that could be perceived.

\section{Funding}

No specific grant from any funding agency.

\section{References}

1. Zhang W, Ouyang $H$, Dass $C R$, et al. Current research on pharmacologic and regenerative therapies for osteoarthritis. Bone Res. 2016; 4: 15040. doi: 10.1038/boneres.2015.40.

2. Wiegant $K$, Intema $F$, van Roermund $P M$, et al. Evidence of cartilage repair by joint distraction in a canine model of osteoarthritis. Arthritis Rheumatol. 2015; 67(2): 465-74. doi: 10.1002/art.38906.

3. Wittenauer R, Smith L, Aden K. Update on 2004 background paper, BP 6.12 osteoarthritis [Internet] written by Tanna S. Priority Medicines for Europe and the World "A Public Health Approach to Innovation"; 2013 Jan 28 ${ }^{\text {th }}$. [Cited 2016 May 4]. Available from: http://www.who.int/medicines/areas/priority_medic ines/BP6_120steo.pdf.

4. Allen KD, Golightly YM. State of the evidence. Curr Opin Rheumatol. 2015; 27(3): 276-83. doi: 10.1097/BOR.0000000000000161.
5. Silverwood V, Blagojevic-Bucknall $M$, Jinks $C$, et al. Current evidence on risk factors for knee osteoarthritis in older adults: a systematic review and meta-analysis. Osteoarthritis Cartilage. 2015; 23(4): 507-15. doi: 10.1016/j.joca.2014.11.019.

6. Watts RA, Conaghan PG, Denton C, et al. Oxford Textbook of rheumatology. 4th ed. UK: Oxford University Press; 2013. p. 1174-86.

7. Abhishek A, Doherty $M$. Diagnosis and clinical presentation of osteoarthritis. Rheum Dis Clin North Am. 2013; 39(1): 45-66. doi: 10.1016/j.rdc.2012.10.007.

8. Mobasheri A, Bay-Jensen AC, van Spil WE, et al. Osteoarthritis year in review 2016: biomarkers (biochemical markers). Osteoarthritis Cartilage. 2017; 25(2): 199-208. doi: 10.1016/j.joca.2016.12.016.

9. Audrey $H X$, Bin Abd Razak HR, Chye Andrew TH. The truth behind subchondral cysts in osteoarthritis of the knee. Open Orthop J. 2014; 8: 7-10. doi: 10.2174/1874325001408010007.

10. Man GS, Mologhianu G. Osteoarthritis pathogenesis - a complex process that involves the entire joint. J Med Life. 2014; 7(1): 37-41.

11. Akkiraju $H$, Nohe A. Role of chondrocytes in cartilage formation, progression of osteoarthritis and cartilage regeneration. J Dev Biol. 2015; 3(4): 177-92. doi: $10.3390 / \mathrm{jdb} 3040177$.

12. Chiba K, Burghardt AJ, Osaki $M$, et al. Threedimensional analysis of subchondral cysts in hip osteoarthritis: an ex vivo HR-pQCT study. Bone. 2014; 66: 140-5. doi: 10.1016/j.bone.2014.06.001.

13. Mathiessen A, Conaghan PG. Synovitis in osteoarthritis: current understanding with therapeutic implications. Arthritis Res Ther. 2017; 19(1): 18. doi: 10.1186/s13075-017-1229-9.

14. Mabey T, Honsawek S. Cytokines as biochemical markers for knee osteoarthritis. World J Orthop. 2015; 6(1): 95-105. doi: 10.5312/wjo.v6.i1.95.

15. Evcik D. Non pharmacological knee osteoarthritis treatment. Annals of Physical and Rehabilitation Medicine. 2015; 58(Suppl 1): e33. doi: https://doi.org/10.1016/j.rehab.2015.07.084.

16. Lui $M$, Jones CA, Westby MD. Effect of non-surgical, non-pharmacological weight loss interventions in patients who are obese prior to hip and knee arthroplasty surgery: a rapid review. Syst Rev. 2015 Sep 27; 4: 121. doi: 10.1186/s13643-015-0107-2.

17. Şahin-Onat Ş, Taşoğlu Ö, Özişler $Z$, et al. Balneotherapy in the Treatment of Knee Osteoarthritis: A Controlled Study. Rheumatol. 2015; (30)4: 292-7.

18. Buttgereit F, Burmester G, Bijlsma JW. Non-surgical management of knee osteoarthritis: where are we now and where do we need to go?. RMD Open. 2015; 1(1): e000027. doi: 10.1136/rmdopen-2014-000027.

19. Marconcin P, Espanha M, Yázigi $F$, et al. The PLE2NO self-management and exercise program for knee osteoarthritis: study protocol for a randomized controlled trial. BMC Musculoskelet Disord. 2016; 17: 250. doi: 10.1186/s12891-016-1115-7. 
20. Noehren B, Dailey DL, Rakel BA, et al. Effect of Transcutaneous Electrical Nerve Stimulation on Pain, Function, and Quality of Life in Fibromyalgia: A Double-Blind Randomized Clinical Trial. Phys Ther. 2015; 95(1): 129-40. doi: 10.2522/ptj.20140218.

21. Mata J, Cabrera $S$, Sanchís $P$, et al. Electroacupuncture for treatment of knee pain from osteoarthritis and the possible endocrinology changes: a study protocol for a randomized controlled trial. Trials. 2015; 16: 248. doi: 10.1186/s13063-015-0766-2.

22. Sharma G, Rathore DS. Potential role of nutraceuticals in the management of knee and hip joint osteoarthritis. Biomedical Science and Engineering. 2015; 3(1): 23-9. doi: 10.12691/bse-3-15.

23. Zhang W, Moskowitz RW, Nuki G, et al. OARSI recommendations for the management of hip and knee osteoarthritis, Part I: critical appraisal of existing treatment guidelines and systematic review of current research evidence. Osteoarthritis Cartilage. 2007; 15(9): 981-1000. doi: 10.1016/j.joca.2007.06.014.

24. Mobasheri A. The future of osteoarthritis therapeutics: targeted pharmacological therapy. Curr Rheumatol Rep. 2013; 15(10): 364. doi: 10.1007/s11926-013-0364-9.

25. Hirsch G, Kitas G, Klocke R. Intra-articular corticosteroid injection in osteoarthritis of the knee and hip: factors predicting pain relief - a systematic review. Semin Arthritis Rheum 2013; 42(5): 451-73. doi: 10.1016/j.semarthrit.2012.08.005.

26. Kielly J, Davis EM, Marra C. Practice guidelines for pharmacists: The management of osteoarthritis. Can Pharm J (Ott). 2017; 150(3): 156-68. oi: $10.1177 / 1715163517702168$.

27. Blanco FJ, Ruiz-Romero C. New targets for disease modifying osteoarthritis drugs: chondrogenesis and Runx1. Ann Rheum Dis. 2013; 72(5): 631-4. doi: 10.1136/annrheumdis-2012-202652.

28. Wehling $P$, Moser $C$, Maixner W. How does surgery compare with advanced intra-articular therapies in knee osteoarthritis: current thoughts. Ther Adv Musculoskelet Dis. 2016; 8(3): 72-85. doi: 10.1177/1759720X16642405.

29. Kapoor M, Martel-Pelletier J, Lajeunesse D, et al. Role of proinflammatory cytokines in the pathophysiology of osteoarthritis. Nat Rev Rheumatol. 2011; 7(1): 3342. doi: 10.1038/nrrheum.2010.196.

30. Goldring $M B$, Otero $M$. Inflammation in osteoarthritis. Curr Opin Rheumatol. 2011; 23(5): 471-8. doi: 10.1097/BOR.0b013e328349c2b1.

31. Scanzello CR, Loeser RF. Inflammatory activity in symptomatic knee osteoarthritis: not all inflammation is local. Arthritis Rheumatol. 2015; 67(11): 2797-800. doi: 10.1002/art.39304.

32. Park SJ, Cheon EJ, Kim HA. MicroRNA-558 regulates the expression of cyclooxygenase-2 and IL-1 $\beta$ induced catabolic effects in human articular chondrocytes. Osteoarthritis Cartilage. 2013; 21(7): 981-9. doi: 10.1016/j.joca.2013.04.012.

33. Sokolove J, Lepus CM. Role of inflammation in the pathogenesis of osteoarthritis: latest findings and interpretations. Ther Adv Musculoskelet Dis. 2013; 5(2): 77-94. doi: 10.1177/1759720X12467868.

34. Wojdasiewicz P, Poniatowski $Ł A$, Szukiewicz D. The role of inflammatory and anti-inflammatory cytokines in the pathogenesis of osteoarthritis. Mediators Inflamm. 2014; 2014: 561459. doi: $10.1155 / 2014 / 561459$.

35. Shafiaa S, Shaha ZA, Sofib FA. TNF-A, IL-1 $\beta$ and IL-6 Cytokine gene expression in synovial fluid of rheumatoid arthritis and osteoarthritis patients and their relationship with gene polymorphisms. Rheumatology (Sunnyvale). 2016; 6: 189. doi:10.4172/2161-1149.1000189.

36. Houard X, Goldring MB, Berenbaum F. Homeostatic mechanisms in articular cartilage and role of inflammation in osteoarthritis. Curr Rheumatol Rep. 2013; 15(11): 375. doi: 10.1007/s11926-013-0375-6.

37. Anand S, Muniappan M, Sangavai $M$, et al. Antiinflammatory activity of telmisartan and rosuvastatin in various animal models. Int J Pharm Pharm Sci. 2014; 6(4):182-6.

38. Laganà AS, Vitale SG, Nigro A, et al. Pleiotropic actions of peroxisome proliferator-activated receptors (PPARs) in dysregulated metabolism homeostasis, inflammation and cancer: current evidence and future perspectives. Int J Mol Sci. 2016; 17(7): 999. doi: 10.3390/ijms17070999.

39. Kostadinova R, Wahli W, Michalik L. PPARs in diseases: control mechanisms of inflammation. Curr Med Chem. 2005; 12(25): 2995-3009.

40. Li X, Afif H, Cheng S, et al. Expression and regulation of microsomal prostaglandin E synthase-1 in human osteoarthritic cartilage and chondrocytes. J Rheumatol. 2005; 32(5): 887-95.

41. Fahmi $H$, Pelletier JP, Mineau $F$, et al. $15 d-P G J 2$ is acting as a 'dual agent' on the regulation of COX-2 expression in human osteoarthritic chondrocytes. Osteoarthritis Cartilage. 2002; 10(11): 845-8.

42. Ma C, Zhang $Y$, Li $Y$, et al. The role of PPARY in advanced glycation end products-induced inflammatory response in human chondrocytes. PLoS One. 2015; 10(5): e0125776. doi: 10.1371/journal.pone.0125776.

43. Cheng $\mathrm{S}$, Afif $\mathrm{H}$, Martel-Pelletier J, et al. Activation of peroxisome proliferator-activated receptor gamma inhibits interleukin-1bata-induced membrane associated prostaglandin E2 synthase-1 expression in human synovial fibroblasts by interfering with Egr-1. J Biol Chem. 2004; 279(21): 22057-65. doi: 10.1074/jbc.M402828200.

44. Nebbaki SS, Mansouri FEL, Afif $\mathrm{H}$, et al. Expression of PPAR $a, b, g$, and $\mathrm{H}$-and L-PGDS during osteoarthritis in the spontaneous Hartley guinea pig and the experimental dog models. Osteoarthritis Cartilage. 2013; 21: S70. https://doi.org/10.1016/j.joca.2013.02.154 
45. Boyault $S$, Simonin MA, Bianchi A, et al. 15-Deoxydelta12,14-PGJ2, but not troglitazone, modulates IL1beta effects in human chondrocytes by inhibiting NF-kappaB and AP-1 activation pathways. FEBS Lett. 2001; 501(1): 24-30.

46. Afif $H$, Benderdour $M$, Mfuna-Endam $L$, et al. Peroxisome proliferator-activated receptor gamma1 expression is diminished in human osteoarthritic cartilage and is downregulated by interleukin-1beta in articular chondrocytes. Arthritis Res Ther. 2007; 9(2): R31. doi: 10.1186/ar2151.

47. Clockaerts S, Bastiaansen-Jenniskens YM, Feijt C, et al. Peroxisome proliferator activated receptor alpha activation decreases inflammatory and destructive responses in osteoarthritic cartilage. Osteoarthritis Cartilage. 2011; 19(7): 895-902. doi: 10.1016/j.joca.2011.03.010.

48. Al-Hejjaj WK, Numan IT, Al-Sa'ad RZ, et al. Antiinflammatory activity of telmisartan in rat models of experimentally-induced chronic inflammation: Comparative study with dexamethasone. Saudi Pharm J. 2011; 19(1): 29-34. doi: 10.1016/j.jsps.2010.10.004.

49. Shieh CS, Tseng CD, Chang LY, et al. Synthesis of vibroarthrographic signals in knee osteoarthritis diagnosis training. BMC Res Notes. 2016; 9: 352. doi: 10.1186/s13104-016-2156-6.

50. Raheem $\mathrm{AH}$. Erythrocyte sedimentation rate in patients with positive sputum for AFB and negative HIV serological test. Muthanna Medical Journal. 2016; 3(1): 17-23.

51.Johnson VL, Hunter DJ. The epidemiology of osteoarthritis. Best Pract Res Clin Rheumatol. 2014; 28(1): 5-15. doi: 10.1016/j.berh.2014.01.004.

52. Su $X, Y u$, Yang $X$, et al. Telmisartan attenuates peritoneal fibrosis via peroxisome proliferatoractivated receptor- $\gamma$ activation in rats. Clin Exp Pharmacol Physiol. 2015; 42(6): 671-9. doi: 10.1111/1440-1681.12403.

53. Sagawa K, Nagatani K, Komagata Y, et al. Angiotensin receptor blockers suppress antigen-specific $T$ cell responses and ameliorate collagen-induced arthritis in mice. Arthritis Rheum. 2005; 52(6): 1920-8. doi: 10.1002/art.21040
54. Araújo AA, Souza TO, Moura LM, et al. Effect of telmisartan on levels of IL-1, TNF- $\alpha$, down-regulated COX-2, MMP-2, MMP-9 and RANKL/RANK in an experimental periodontitis model. J Clin Periodontol. 2013; 40(12): 1104-11. doi: 10.1111/jcpe.12160.

55. Torika N, Asraf K, Danon A, et al. Telmisartan modulates glial activation: in vitro and in vivo studies. PLoS One. 2016; 11(5): e0155823. doi: 10.1371/journal.pone.0155823.

56. Guerra GC, Araújo AA, Lira GA, et al. Telmisartan decreases inflammation by modulating TNF- $\alpha, \mathrm{IL}-10$, and RANK/RANKL in a rat model of ulcerative colitis. Pharmacol Rep. 2015; 67(3): 520-6. doi: 10.1016/j.pharep.2014.12.011.

57. Kang C, Yijun L, Jingtao D, et al. Effects of telmisartan on lipid metabolisms and proinflammatory factors secretion of differentiated 3T3-L1 adipocytes. J Renin Angiotensin Aldosterone Syst. 2015; 16(4): 1061-8. doi: 10.1177/1470320313518252.

58. Goyal BR, Mehta AA. Beneficial role of spironolactone, telmisartan and their combination on isoproterenol-induced cardiac hypertrophy. Acta Cardiologica. 2012, 67(2): 203-11. DOI: 10.2143/AC.67.2.2154211.

59. Song Z, Bai J, Zhang L, et al. [Effects of telmisartan on inflammation and fibrosis after acute myocardial infarction in rats]. Zhonghua Yi XueZaZhi. 2014; 94(33): 2628-33.

60. Ucciferri C, Falasca K, Mancino $P$, et al. Microalbuminuria and hypertension in HIV-infected patients: a preliminary study of telmisartan. Eur Rev Med Pharmacol Sci. 2012; 16(4): 491-8.

Correspondence to
Dr. Mohammed M. Mohammed
E-mail:
pharm.drmhdclinical@uomustansiriyah.edu.iq
phd_pharm@yahoo.com
Received Sep. $28^{\text {th }} 2017$
Accepted Nov. 16 2017

